УДК 541.64:542.06

DOI: https://doi.org/10.17308/kcmf.2019.21/761

Поступила в редакцию 14.03.2019

Подписана в печать 15.05.2019

\title{
СИНТЕЗ ГРАФТ-СОПОЛИМЕРОВ НАТРИЕВОЙ СОЛИ КАРБОКСИМЕТИЛЦЕЛЛЮЛОЗЫ С $N$-ВИНИЛИМИДАЗОЛОМ И ИССЛЕДОВАНИЕ СВОЙСТВ ИХ ВОДНЫХ ДИСПЕРСИЙ
}

\author{
(c) 2019 В. А. Кузнецов, М. С. Лавлинская $\bowtie$, А. В. Сорокин \\ Воронежский государственный университет \\ Университетская пл., 1, 394018 Воронеж, Российская Федерация
}

\begin{abstract}
Аннотация. Радикальной полимеризацией в присутствии пероксида водорода получены графт-сополимеры натриевой соли карбоксиметилцеллюлозы и $N$-винилимидазола. Структура полученных продуктов подтверждена методом ИК-спектроскопии. Методами просвечивающей электронной микроскопии, динамического светорассеяния и лазерного допплеровского микроэлектрофореза установлено, что частицы дисперсий сополимеров имеют несферическую форму и отрицательный электрокинетический потенциал. Изучено влияние присутствие хлорида натрия на гидродинамический радиус частиц полимеров.
\end{abstract}

Ключевые слова: графт-сополимеры, карбоксиметилцеллюлоза, $N$-винилимидазол, полимерные дисперсии.

\section{ВВЕДЕНИЕ}

Макромолекулярный дизайн является одним из основных направлений современной полимерной науки. Создание полимеров различной архитектуры позволяет не только показать синтетические возможности исследователей, но и значительно расширить области применения полученных материалов. Так, например, используя контролируемую радикальную полимеризацию, становиться возможным получение сополимеров с упорядоченным блочным расположением мономерных звеньев и узким молекулярно-массовым распределением [1]. Хорошо известно, что в случае классической радикальной полимеризации подобного результата достичь чрезвычайно трудно.

Одним из перспективных направлений применения полимеров со сложной архитектурой и композитов на их основе является использование их в качестве векторов для целевой доставки лекарственных средств. Особенно актуально создание таких лекарственных форм в случае противоопухолевой терапии, когда для лечения применяются цитостатики - токсичные вещества, губительно воздействующие на весь организм. Создание лекарственных форм на основе полимеров способствует снижению

$\triangle$ Лавлинская Мария Сергеевна,

e-mail: maria.lavlinskaya@gmail.com токсичности последних и пролонгации их действия [2-4].

К таким полимерам предъявляется ряд особых требований, таких как низкая токсичность, биосовместимость и наличие способности к образованию ассоциатов с лекарственными веществами. Не менее важны размеры полимерных частиц и их устойчивость в водно-солевой среде, определяющие способность проникновения к пораженным тканям комплекса полимер-лекарственное вещество, а также выведение последнего из организма.

Наиболее полно приведенным выше требованиям отвечают полисахариды. Широкое применение в качестве инертного носителя цитостатиков в противоопухолевой терапии находит доступное модифицированное производное целлюлозы - натриевая соль карбоксиметилцеллюлозы - в виде концентрированного водного раствора. Солевая форма обладает таким преимуществом, как относительно быстрое растворение в воде, что значительно облегчает производство лекарственных форм на ее основе. Кроме того, такие формы обладают противоспаечным действием и способствуют регенерации тканей. Регулировать количество вносимого препарата возможно посредством контролирования связывания полимера с последним. Способность полимера образовывать ас- 
социаты связана с количеством стерически доступных функциональных групп, взаимодействующих с лигандом. Повысить их содержание в макромолекуле возможно путем проведения сополимеризации, приводящей в зависимости от условий к продуктам различной архитектуры. При полимеризации в присутствии мощных окислителей и высоких температурах основным продуктом реакции являются макромолекулы сополимеров блочного строения, в более мягких условиях образуются преимущественно графт-сополимеры.

Перспективными сомономерами для получения полимеров-носителей являются $N$-винилазолы, например, поли- $N$-винилимидазол, хорошо известный своей высокой комплексообразующей способностью и низкой токсичностью, а также каталитической активностью [5-7].

В связи с чем, цель данной работы - синтез графт-сополимеров карбоксиметилцеллюлозы в форме ее натриевой соли с $N$-винилимидазолом и изучение поведения их водных дисперсий в широком диапазоне величин $\mathrm{pH}$ и присутствии солей.

\section{ЭКСПЕРИМЕНТАЛЬНАЯ ЧАСТЬ}

В работе использовались натриевая соль карбоксиметилцеллюлозы (КМЦ) с молекулярной массой $M_{W}=20000$ и товарный мономер $N$-винилимидазол (ВИ) (все Sigma Aldrich, Германия), характеризуется $T_{\text {кип }}=78-79^{\circ} \mathrm{C} / 11 \mathrm{~mm}$ $\mathrm{Hg} ; \rho=1.0382 \mathrm{~g} / \mathrm{cm}^{3}\left(25^{\circ} \mathrm{C}\right) ; n_{\mathrm{D}}^{20}=1.5338$, товарный мономер непосредственно перед синтезом перегоняли с добавлением ингибитора гидрохинона под вакуумом, отбирая фракцию 64$66^{\circ} \mathrm{C} / 2.5 \mathrm{~mm} \mathrm{Hg}$, что отвечает литературным данным [5].

Синтез осуществлялся по методике, описанной в работе [5]. Выход продуктов находился в интервале 71-79\% (табл. 1).

Состав сополимеров определялся методом ИК-спектроскопии, учитывая соотношение величин площадей под полосами поглощения, относящихся к колебаниям >C=O-групп КМЦ и >C=N- групп имидазольного цикла при 1744 и $1456 \mathrm{~cm}^{-1}$ соответственно. ИК-спектры получены на приборе Bruker Vertex 70 (Bruker Optics, Германия) с Фурье-преобразователем методом нарушенного полного внутреннего отражения в диапазоне частот 400-4000 $\mathrm{cm}^{-1}$.

Эффективность прививки (ЭП) рассчитывали по следующей формуле [8]:

$$
\text { ЭП }=\frac{m_{2}-m_{1}}{m_{1}} \times 100
$$

где $m_{1}$ и $m_{2}$ масса очищенного и высушенного графт-сополимера и масса $\mathrm{Na}-\mathrm{KM}, \mathrm{g}$, соответственно.

Для изучения кинетики полимеризации использовали метод УФ-спектроскопии. УФ-спектры водных растворов получены на спектрофотометре Shimadzu UV 1800 (Shimadzu Scientific Instruments, Япония). В течение 3 часов через каждые 15 минут из реакционной массы отбирали пробы объемом $0.5 \mathrm{~cm}^{3}$ для последующего изучения процесса полимеризации. Отобранные из реакционной массы пробы помещали в пробирку, содержащую 5 сm³ ДМФА, взбалтывали, выделившийся осадок отделяли на воронке Бюхнера, промывали медицинским эфиром, сушили в вакуумном сушильном шкафу в течение часа, взвешивали, после чего растворяли в дистиллированной воде в мерной колбе на $50 \mathrm{~cm}^{3}$. Перед получением УФ-спектров полученный раствор дегазировали на УЗ-ванне в течение $10 \mathrm{~min}$, после чего заполняли колбы аргоном. Учитывались заранее определенные максимумы светопоглощения водных дисперсий сополимеров $\lambda_{\max }$ при $202 \mathrm{~nm}$ для звеньев ВИ. Определение содержания звеньев различного типа проводилось с помощью градуировочного графика.

Для определения молекулярной массы привитых цепей ВИ сополимеры растворяли в $0.1 \mathrm{~N}$ растворе $\mathrm{NaNO}_{2}$, добавляли эквимольное количество $0.1 \mathrm{~N}$ раствора $\mathrm{HCl}$, раствор выдерживали в течение суток. Затем смесь осаждали в ацетоне, осадок отфильтровывали и сушили в вакуумном сушильном шкафу до постоянной массы.

Молекулярные массы образовавшихся полимеров определяли методом гель-проникающей хроматографии с помощью хроматографического комплекса, состоящего из двух инертных изократических насосов (АКВИЛОН ВЭЖХ насос

Таблица 1. Условия синтеза графт-сополимеров КМЦ-ВИ

[Table 1. Synthesis conditions for Na-CMC-g-VI copolymers]

\begin{tabular}{|c|c|c|c|c|c|}
\hline \multirow{2}{*}{$\begin{array}{c}\text { № } \\
\Pi / \Pi \\
{[\mathrm{No}]}\end{array}$} & \multirow{2}{*}{ 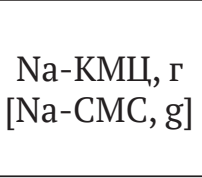 } & \multicolumn{3}{|c|}{$\begin{array}{l}\mathrm{BИ,} \\
{[\mathrm{VI}]}\end{array}$} & \multirow{2}{*}{$\begin{array}{c}\text { Выход, } \\
\% \\
\text { [Yield, } \\
\%]\end{array}$} \\
\hline & & $\begin{array}{l}\mathrm{v}, \text { моль } \\
{[\mathrm{v}, \mathrm{mol}]}\end{array}$ & $\begin{array}{c}m, \Gamma \\
{[m, g]}\end{array}$ & $\begin{array}{c}V, \text { мл } \\
{[V, \mathrm{ml}]}\end{array}$ & \\
\hline 1 & 1.000 & 0.005 & 0.50 & 0.48 & 73 \\
\hline 2 & 1.000 & 0.010 & 1.00 & 0.96 & 74 \\
\hline 3 & 1.000 & 0.015 & 1.50 & 1.44 & 71 \\
\hline 4 & 1.000 & 0.030 & 3.00 & 2.88 & 78 \\
\hline 5 & 1.000 & 0.040 & 4.00 & 3.84 & 77 \\
\hline 6 & 1.000 & 0.050 & 5.00 & 4.80 & 79 \\
\hline
\end{tabular}


серии 2), устройства автоматического ввода образца Jetchrom с функцией переключения 4-х линий низкого давления Автоблок-04, детектора VUV-25 Dual Wavelength VIS Detector и колоночного модуля с термостатом колонок (АКВИЛОН TS10), колонки для ВЭЖХ С-18 $150 \mathrm{~mm} \times 4.6 \mathrm{~mm} \times$ $5 \mathrm{~mm}$ PATHFINDER NQ, петли инжектора $10 \mu \mathrm{L}$, оснащенного программным обеспечением Portlab 30X с функцией управления перистальтическими насосами, устройством Автоблок-04 Jetchrom, системами ВЭЖХ Стайер и Jetchrom. В качестве подвижной фазы использовалась смесь ацетонитрила с водой, калибровали по полистирольным стандартам. Для подтверждения результатов молекулярную массу $M_{\mathrm{w}}$ привитых цепей также определяли методом статического светорассеяния [9].

Электрокинетический потенциал частиц полимера и величину плотности заряда $m_{\mathrm{e}}$ водных дисперсий определяли с помощью лазерного капиллярного допплеровского микроэлектрофореза на приборе Malvern Zetasizer Nano (Malvern Instruments, Великобритания) в кюветах, оснащенных золотым электродом.

Данные по динамическому светорассеянию (ДРС) получали на модульном спектрометре динамического и статического рассеяния света Photocor-Complex (Фотокор, Россия) в кварцевых кюветах, оборудованном Не-Ne лазером мощностью $25 \mathrm{~mW}$ и длиной волны $\lambda=632.8 \mathrm{~nm}$. Съемка осуществлялась под углом $90^{\circ}$ при $25^{\circ} \mathrm{C}$, время измерения составляло 120 секунд. Расчеты вели с использованием программного обеспечения DynaLS. Для расчета значения радиуса инерции использовали метод статического светорассеяния, съемку осуществляли под разными углами в диапазоне $20-130^{\circ}$ при $25^{\circ} \mathrm{C}$, полученные данные также обрабатывали с помощью пакета DynaLS.

Для определения размера и формы полимерных частиц дисперсий использовали метод просвечивающей электронной микроскопии (ПЭМ), при помощи электронного микроскопа Libra 120 (Carl Zeiss, Германия). Перед проведением съемки дисперсию полимера по каплям наносили на медную пластину, покрытую формваром, высушивали в токе воздуха в течение минуты, избыток дисперсии удаляли промоканием. Затем наносили контрастный агент (1\%-ный раствор ацетата уранила), промокали и сушили в токе воздуха.

Изучение влияния присутствия электролита на размер частиц сополимеров КМЦ-ВИ осуществлялось с помощью прибора Photocor Com- plex. В водный раствор $0.15 \mathrm{~N} \mathrm{NaCl}$ помещали $5 \mathrm{~cm}^{3}$ дисперсии сополимера с концентрацией $0.1 \mathrm{mg} / \mathrm{cm}^{3}$ и фиксировали изменение гидродинамического радиуса частиц в течение 60 минут. Выбор интервала концентрации соли обусловлен корреляцией с их максимальным содержанием в плазме крови человека. Аналогичным способом исследовали влияние $\mathrm{pH}$ среды в интервале от 1 до 12 на изменение гидродинамического радиуса. Реакцию среды дисперсий сополимеров определяли посредством $\mathrm{pH}$-метрии, с помощью pH-метра Анион-4100 (Инфраспак-Аналит, Россия), оснащенного комбинированным электродом серии ЭСК и термодатчиком.

\section{РЕЗУЛЬТАТЫ И ИХ ОБСУЖДЕНИЕ}

Сополимеры натриевой соли карбоксиметилцеллюлозы с $N$-винилимидазалом с различным содержанием звеньев последнего получали радикальной полимеризацией в водном растворе в присутствии пероксида водорода (табл. 1). Инициирование протекало по окислительновосстановительному механизму, где окислителем выступал пероксид водорода, а восстановителем - пиранозные циклы КМЦ. Процесс проводили в мягких условиях, без нагревания, что, согласно литературным данным [10], должно приводить к образованию привитого сополимера. Продукты реакции выделяли трехкратным осаждением в ДМФА. Выбор осадителя обусловлен тем, что в нем растворяется Na-КМЦ и поли- и $N$-винилимидазол, что позволяет добиться очистки целевого продукта от побочных компонентов. Выход полученных продуктов лежит в интервале 71-79\%.

Структуру полученных продуктов подтверждали с помощью ИК-спектроскопии. В ИК-спектрах сополимеров Na-КМЦ-ВИ присутствуют характеристические полосы поглощения в области $1100-1200 \mathrm{~cm}^{-1}$, относящиеся к колебаниям полисахаридных фрагментов, $1456 \mathrm{~cm}^{-1}$, соответствующие колебаниям связи $\mathrm{C}=\mathrm{N}$ имидазольного цикла, $1744 \mathrm{~cm}^{-1}$, характерные для валентных колебания $\mathrm{C}=\mathrm{O}$ групп $\mathrm{Na}-\mathrm{KMЦ,} \mathrm{колебания} \mathrm{угле-}$ родного скелета поливинилимидазольной цепи при 2800-2900 $\mathrm{cm}^{-1}$, также присутствует широкая полоса поглощения в области $3200-3300 \mathrm{~cm}^{-1}$, соответствующая колебаниям ОН-групп ассоциированных молекул воды. Составы сополимеров, определенные на основании спектральных данных, представлены в табл. 2.

Изучение кинетики полимеризации путем определения состава образующегося сополимера методом УФ-спектроскопии показало, что в 
Таблица 2. Характеристика синтезированных графт-сополимеров

[Table 2. Characterization of synthesized Na-CMC-g-VI copolymers]

\begin{tabular}{|c|c|c|c|c|c|c|c|}
\hline \multirow{2}{*}{$\begin{array}{c}\text { № } \\
\text { П/П } \\
\text { [No] }\end{array}$} & \multirow{2}{*}{$\begin{array}{l}\text { Полимеризационная смесь, } \\
\text { Na-КМЦ:ВИ, масс. частей } \\
\text { [Polymerization mixture, } \\
\text { Na-CMC:VI, w:w] }\end{array}$} & \multirow{2}{*}{$\begin{array}{c}\text { ВИ в сополимере, } \\
\text { \% масс } \\
\text { [VI in copolymer, } \\
\% \text { w] }\end{array}$} & \multirow{2}{*}{$\begin{array}{l}\text { ЭП, \% } \\
{[\mathrm{GE}, \%]}\end{array}$} & \multicolumn{4}{|c|}{$\begin{array}{c}\text { Привитые цепи ПВИ } \\
\text { [Grafted PVI chains] }\end{array}$} \\
\hline & & & & $M_{n}$ & $\mathrm{M}_{\mathrm{w}}$ & PDI & $\mathrm{M}_{\mathrm{w}}^{*}$ \\
\hline 1 & $1: 0.5$ & 27 & 81 & 9896 & 10985 & 1.11 & 11103 \\
\hline 2 & $1: 1$ & 43 & 86 & 13542 & 15573 & 1.15 & 15264 \\
\hline 3 & $1: 1.5$ & 47 & 78 & 15678 & 17716 & 1.13 & 17803 \\
\hline 4 & $1: 3$ & 58 & 77 & 17542 & 20349 & 1.16 & 21085 \\
\hline 5 & $1: 4$ & 61 & 76 & 19452 & 21786 & 1.12 & 22723 \\
\hline 6 & $1: 5$ & 62 & 75 & 20103 & 22917 & 1.14 & 22869 \\
\hline
\end{tabular}

случае всех выбранных соотношений компонентов реакция практически завершается по истечению 160 минут, и дальнейшее выдерживание реакционной смеси приводит к незначительному изменению состава сополимера (рис. 1). Дальнейшее увеличение времени процесса нецелесообразно, так как при больших степенях превращения процесс графт-сополимеризации осложняется вторичными процессами, связанными с изменением механизма обрыва цепи и образованием сетчатых сополимеров сложной структуры. Доказательством этого является получение при высоких степенях превращения нерастворимых в воде золь-фракций, для которых характерна сильная набухаемость.
Расчет эффективности процесса прививки позволил заключить, что в случае внесения небольших количеств ВИ (0.5-1.5 масс. частей) практически весь мономер участвует в образовании графт-сополимера. С увеличением содержания ВИ в начальной полимеризационной смеси, и как следствие, повышением общей концентрации раствора, незначительно возрастает тенденция азолсодержащего мономера к гомополимеризации. Величины молекулярных масс привитых цепей поли- $N$-винилимидазола (ПВИ), определенные методами гель-проникающей хроматографии и статического светорассеяния, хорошо согласуются между собой и возрастают с увеличением концентрации мономера в исход-

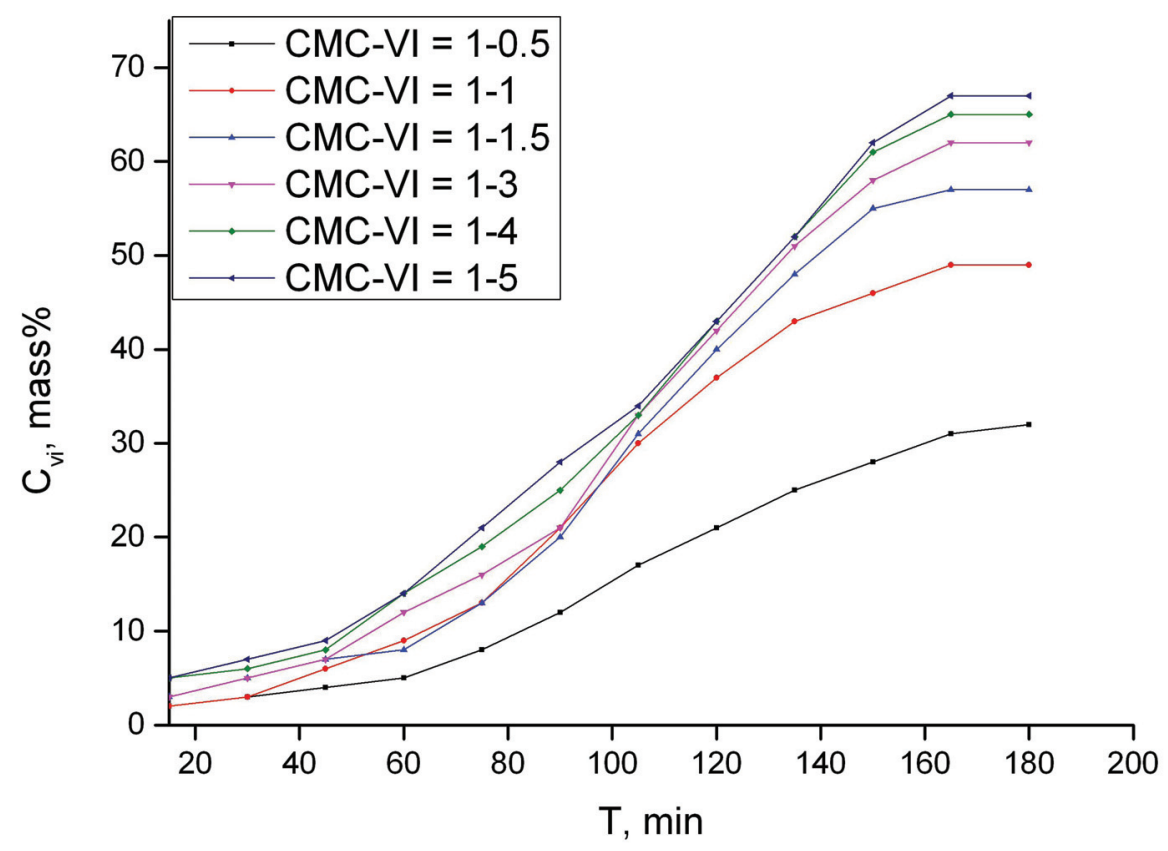

Рис. 1. Кривые конверсии графт-сополимеров

[Fig. 1. Graft-copolymer's conversion curves] 
ной полимеризационной смеси (табл. 2). Стоит отметить, привитые цепи обладают довольно малым значением индекса полидисперсности (PDI) для продуктов, полученных в условиях радикального процесса.

Хорошо известно, что азольные циклы характеризуются склонностью к кислотно-основному взаимодействию за счет электронодонорных свойств «пиридинового» атома азота и электроноакцепторных свойств ненасыщенной $\pi$-системы [11]. В то же время, макромолекулы натриевой соли карбоксиметилцеллюлозы проявляют кислотные свойства. В связи с этим целесообразно изучить свойства водных дисперсий синтезированных графт-сополимеров.

Исследование размеров частиц сополимеров в разбавленных водных дисперсиях показало, что макромолекулярные клубки полимеров, имеющие гидродинамический радиусы $R_{\mathrm{h}} 120-$ $152 \mathrm{~nm}$, находятся в виде ассоциатов, и с увеличением содержания звеньев ВИ величина $R_{\mathrm{h}}$ возрастает незначительно (табл. 3). Одновременно с $R_{\mathrm{h}}$ возрастает и величина радиуса инерции $R_{\mathrm{g}}$, что свидетельствует об увеличении размеров частиц за счет большей длины боковых звеньев ВИ. Величина отношения $R_{\mathrm{g}} / R_{\mathrm{h}}$ показывает, что независимо от длины боковых цепей форма частиц дисперсии отклонена от сферической, что обусловлено жесткоцепным характером макромолекул КМЦ. Данные просвечивающей электронной микроскопии (рис. 2) подтверждают результаты, полученные с помощью метода динамического светорассеяния.

Одной из важнейших характеристик, определяющих устойчивость дисперсной системы, является величина электрокинетического потенциала. Из табл. 3 видно, что частицы синтезированных сополимеров характеризуются совокупным отрицательным $\zeta$-потенциалом. С увеличением содержания звеньев ВИ в сополимере величина отрицательного заряда снижается, что объясняется компенсацией отрицательного заряда карбоксильных групп КМЦ положительно заряженными звеньями ВИ. На это же указывает значение объемной плотности заряда $m_{\mathrm{e}}$, которое снижается с увеличением содержания звеньев ВИ. Следует отметить, что при содержании звеньев ВИ 27 и 43 \% масс дисперсии сополимеров относятся к сильно заряженным золям, а остальные - к слабо заряженным.

Важной характеристикой, определяющей возможность использования полимера в качестве носителя лекарственного препарата, является его устойчивость к воздействию солей, входящих в состав плазмы крови, а так же к изменениям величины рН среды. На рис. 3 представлена зависимость гидродинамических радиусов полимерных частиц от присутствия $0.15 \mathrm{~N}$ раствора $\mathrm{NaCl}$. Из представленных данных видно, что в течение проведения исследования частицы сополимеров в растворе электролита сохраняют практически неизменный гидродинамический

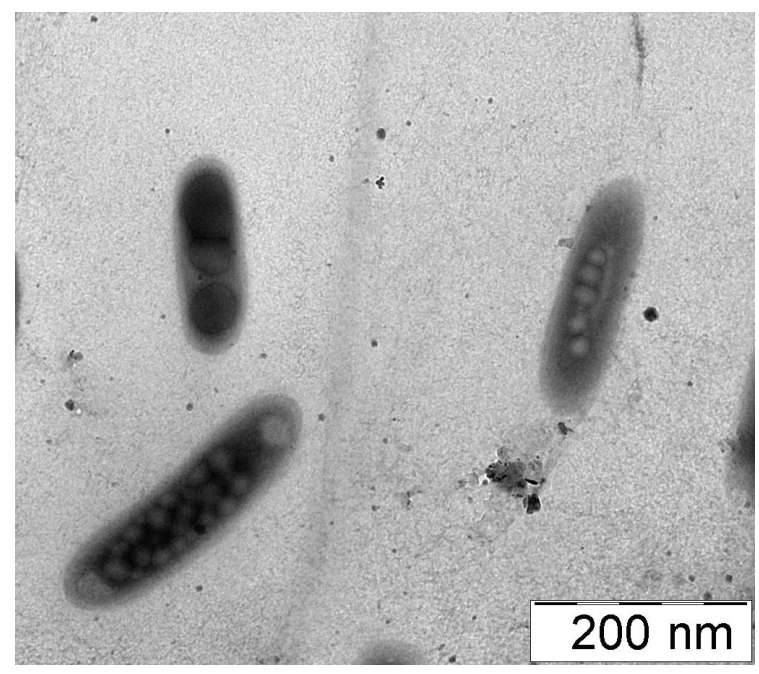

Рис. 2. ПЭМ изображение частиц дисперсий сополимера КМЦ-ВИ

[Fig. 2. TEM image of Na-CMC-g-VI copolymer's particles in aqueous solution]

Таблица 3. Свойства водных дисперсий синтезированных сополимеров КМЦ-ВИ

[Table 3. Properties of aqueous solutions of synthesized Na-CMC- $g$-VI copolymers]

\begin{tabular}{|c|c|c|c|c|c|c|c|}
\hline $\begin{array}{c}\text { № } \\
\text { П/П } \\
{[\text { No] }}\end{array}$ & $\begin{array}{c}\text { Содержание ВИ в сополимере, } \\
\text { \% масс } \\
\text { [Vi in copolymer, \% w] }\end{array}$ & $R_{\mathrm{h}}, \mathrm{nm}$ & $R_{\mathrm{g}}, \mathrm{nm}$ & $R_{\mathrm{g}} / R_{\mathrm{h}}$ & $\mathrm{pH}$ & $\zeta, \mathrm{mV}$ & $m_{\mathrm{e}}, \mu \mathrm{mcm} / \mathrm{Vs}$ \\
\hline 1 & 27 & 120 & 178 & 1.48 & 6.86 & -45.1 & -3.312 \\
\hline 2 & 43 & 130 & 190 & 1.46 & 6.42 & -30.8 & -2.315 \\
\hline 3 & 47 & 141 & 210 & 1.49 & 6.40 & -17.2 & -1.350 \\
\hline 4 & 58 & 148 & 222 & 1.50 & 6.35 & -13.1 & -1.308 \\
\hline 5 & 61 & 149 & 219 & 1.47 & 6.35 & -10.2 & -1.241 \\
\hline 6 & 62 & 152 & 225 & 1.48 & 6.33 & -9.6 & -1.187 \\
\hline
\end{tabular}


радиус (менее $160 \mathrm{~nm}$ ), что делает возможным использование полученных сополимеров в качестве носителей лекарственных веществ для инфузионного введения.

Изучение влияния $\mathrm{pH}$ на размеры агрегированных макромолекулярных клубков показало, что с возрастанием $\mathrm{pH}$ гидродинамические радиусы уменьшаются (рис. 4). Такое поведение может быть объяснено кислотно-основными взаимодействиями, характерными для имидазольных циклов и карбоксиметилцеллюлозы. В кислой среде азольные циклы звеньев ВИ протонируются, приобретая положительный заряд, в результате чего происходит их взаимное отталкивание и увеличение размеров полимерных частиц. В щелочной среде звенья ВИ слабо про-

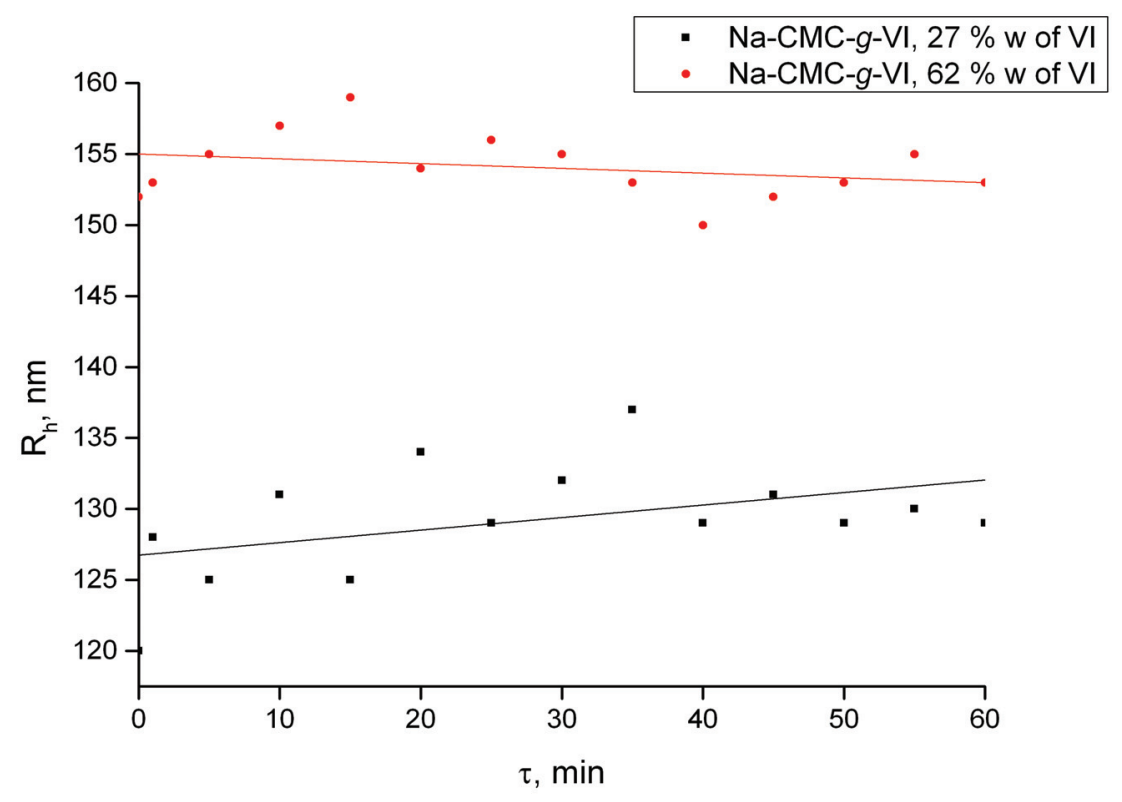

Рис. 3. Зависимость гидродинамического радиуса частиц сополимеров КМЦ-ВИ от времени в присутствии $0.15 \mathrm{~N} \mathrm{NaCl}$

[Fig. 3. Dependency of hydrodynamic radius of Na-CMC- $g$-VI copolymer's particles on time in a presence $0.15 \mathrm{~N} \mathrm{NaCl}]$

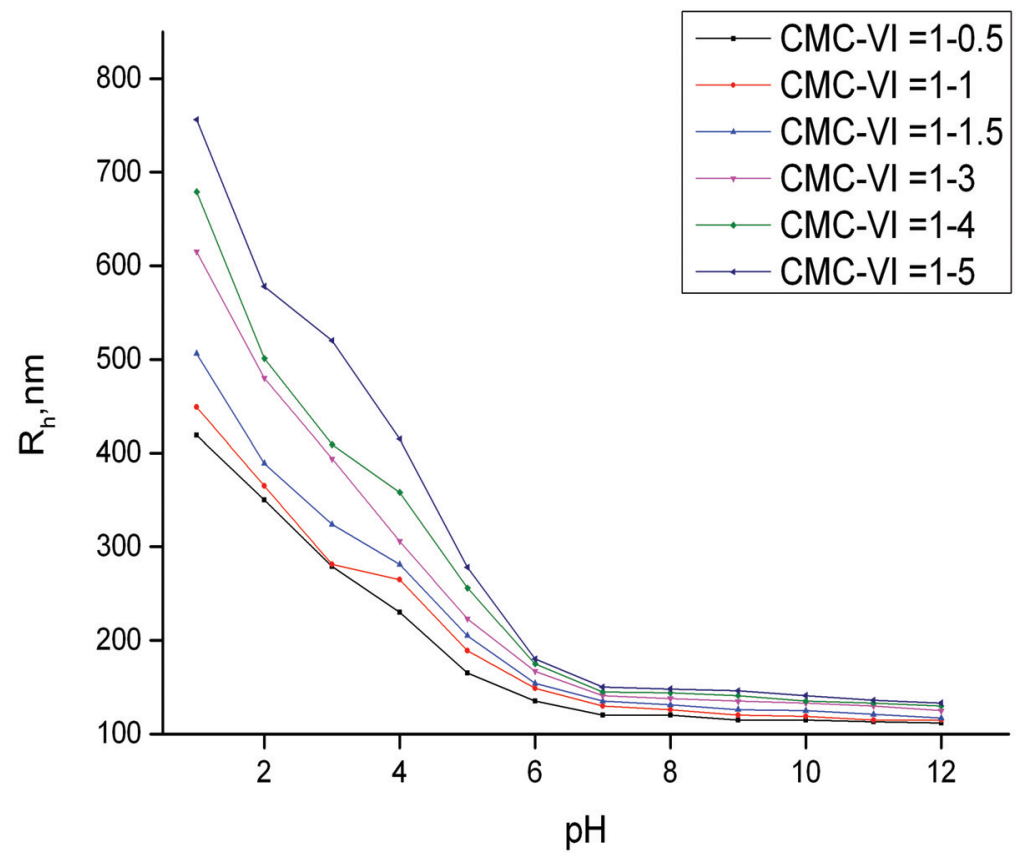

Рис. 4. Зависимость гидродинамического радиуса частиц сополимера КМЦ-ВИ от величины рН [Fig. 4. Dependency of hydrodynamic radius of Na-CMC- $g$-VI copolymer's particles on $\mathrm{pH}$ value] 
тонированы, а полимерная матрица КМЦ за счет сильно диссоцированной карбоксильной группы приобретает отрицательный заряд, вызывая частичное притяжение привитых цепей ПВИ, что способствует уменьшению размеров частиц.

\section{ЗАКЛЮЧЕНИЕ}

Таким образом, получены графт-сополимеры натриевой соли карбоксиметилцеллюлозы и $N$-винилимидазола с различным содержанием звеньев последнего. Частицы дисперсии синтезированных сополимеров имеют несферическую форму, что подтверждается методами ДСР и ПЭМ, а также отрицательное значение электрокинетического потенциала. Размеры частиц сополимеров практически не меняются при воздействии раствора $0.15 \mathrm{~N}$ хлорида натрия и изменения рН в физиологическом интервале значений и лежат в интервале $120-152 \mathrm{~nm}$, что делает возможным использование полученных сополимеров в качестве векторов для доставки лекарственных средств.

\section{БЛАГОДАРНОСТИ}

Данные ИК-спектроскопии, просвечивающей электронной микроскопии, лазерного допплеровского микроэлектрофореза получены на оборудовании Центра коллективного пользования научным оборудованием ВГУ.

\section{КОНФЛИКТ ИНТЕРЕСОВ}

Авторы декларируют отсутствие явных и потенциальных конфликтов интересов, связанных с публикацией настоящей статьи.

\section{СПИСОК ЛИТЕРАТУРЫ}

1. Madruga E. From classical to living/controlled statistical free-radical copolymerization // Prog. Polym. Sci., 2002, v. 27, pp. 1879-1924. DOI: 10.1016/S00796700(02)00023-0

2. Barouti G., Jaffredo C. G., Guillaume S. M. Advances in drug delivery systems based on synthetic poly(hydroxybutyrate) (co)polymers // Prog. Polym.
Sci., 2017, v. 73, pp. 1-31. DOI: 10.1016/j.progpolymsci.2017.05.002

3. Kabanov A. V., Vinogradov S. V. Nanogels as pharmaceutical carriers: finite networks of infinite capabilities // Angew. Chem. Int. Ed., 2009, v. 48, pp. 5418-5429. DOI: 10.1002/anie.200900441

4. Oh J. K., Drumright R., Siegwart D., Matyjaszewski K. The development of microgels/nanogels for drug delivery applications // Prog. Polym. Sci., 2008, v. 33, pp. $448-477$. DOI: $10.1016 / \mathrm{j}$.progpolymsci.2008.01.002

5. Kuznetsov V. A., Lavlinskaya M. S., Ostankova I. V. Synthesis of $\mathrm{N}$-vinylformamide and 1-vinyl-(1methacryloyl)-3,5-dimethylpyrazole copolymers and their extraction ability in relation to histidine in watersalt media // Polym. Bull., 2018, v. 75, pp. 1237-1251. DOI: $10.1007 / \mathrm{s} 00289-017-2091-2$

6. Bhattacharya A., Misra B. Grafting: a versatile means to modify polymersTechniques, factors and applications // Prog. Polym. Sci., 2004, v. 29, pp. 767814. DOI: $10.1016 /$ j. progpolymsci.2004.05.002

7. Rasoulzadeh M., Namaz H. Carboxymethyl cellulose/graphene oxide bio-nanocomposite hydrogel beads as anticancer drug carrier agent // Carbohydr. Polym., 2017, v. 168, pp.320-326. DOI: 10.1016/j.carbpol.2017.03.014

8. Worzakowska M. Chemical modification of potato starch by graft copolymerization with citronellyl methacrylate // J. Polym. Environ., 2018, v. 26, pp. 16131624. DOI: 10.1007/s10924-017-1062-X

9. Kuznetsov V. A., Kushchev P. O., Blagodatskikh I. V. Aqueous dispersions of cross-linked poly$\mathrm{N}$-vinylcaprolactam stabilized with hydrophobically modified polyacrylamide: synthesis, colloidal stability, and thermosensitive properties // Colloid. Polym. Sci., 2016, v. 294, pp. 889-899. DOI: 10.1007/s00396016-3843-5

10. Genç F., Uzun C., Güven O. Quaternized poly(1vinylimidazole) hydrogel for anion adsorption // Polym. Bull., 2016, v. 73, pp. 179-190. DOI: 10.1007/s00289015-1479-0

11. Jakubiak-Marcinkowska A, Legan M, Jezierska J. Molecularly imprinted polymeric $\mathrm{Cu}$ (II) catalysts with modified active centres mimicking oxidation enzymes // J. Polym. Res., 2013, v. 20(12), pp. 317-328. DOI: $10.1007 / \mathrm{s} 10965-013-0317-\mathrm{z}$ 
UDC 541.64:542.06 4

DOI: https://doi.org/10.17308/kcmf.2019.21/761

Received 14.03.2019

Accepted 15.05.2019

\title{
SYNTHESIS OF CARBOXYMETHYL CELLULOSE SODIUM SALT AND $N$-VINYLIMIDAZOLE GRAFT COPOLYMERS AND THEIR AQUEOUS SOLUTIONS PROPERTY RESEARCHING
}

\author{
¡2019 V. A. Kuznetsov, M. S. Lavlinskaya $₫$, A. V. Sorokin \\ Voronezh State University \\ 1, Universitetskaya pl., 394018 Voronezh, Russian Federation
}

\begin{abstract}
Purpose. The aim of this work is synthesis of carboxymethyl cellulose sodium salt (Na-CMC) and $N$-vinylimidazole (VI) graft copolymers and investigation of the properties of their water solutions.

Methods and methodology. The Na-CMC-g-VI co-polymers with different content of VI were obtained by free radical polymerization with ox-red initiator system (Table 1). Selective precipitation and dialysis were used to remove unreacted Na-CMC, VI and other excess components.

Results. The structure, compound and grafting efficiency (GE) of the synthesized co-polymers were determined by Fourier transmission infrared spectroscopy (Table 1). Polymerization kinetics for all samples is researched by co-polymer composition determination with UV spectroscopy use, and was found that it was ending during 180 minutes (Fig. 1) Molecular weights of grafted poly- $N$-vinylimidazole were calculated from gel permeation chromatography static light scattering data. It was found that GE value is maximal for co-polymer containing $43 \% \mathrm{w}$ of VI (Table 2). Dynamic light scattering (DLS) and transmission electron microscopy researching showed that particles of all synthesized co-polymers in water possess non-spherical form (Fig. 2), and their surfaces have negative values of zeta-potential (Table 3). The hydrodynamic radii of the polymer particles are in the range of $120-152 \mathrm{~nm}$, and slightly increase with VI content growth. It was found by DLS that polymer particles of all co-polymers are stable in $0.15 \mathrm{M} \mathrm{NaCl}$ aqueous solution and in the wide $\mathrm{pH}$ range which allows to apply them as vectors for targeted drug delivery (Fig. 3, 4).

Conclusion. To sum up, Na-CMC- $g$-VI co-polymers were prepared by free radical copolymerization with ox-red initiator system. Aqueous solutions of the synthesized co-polymers were characterized by dynamic light scattering, transmission electron microscopy and zeta-potential measurement.
\end{abstract}

Keywords: graft copolymers, carboxymethyl cellulose, $N$-vinylimidazole, polymer solutions.

\section{ACKNOWLEDGMENTS}

FTIR, TEM, zeta-potential data were obtained with use of equipment of Center of collective usage of scientific equipment of Voronezh State University.

\section{CONFLICT OF INTEREST}

The authors declare the absence of obvious and potential conflicts of interest related to the publication of this article.

$\checkmark$ Lavlinskaya Maria Sergeevna

e-mail: maria.lavlinskaya@gmail.com

\section{REFERENCES}

1. Madruga E. From classical to living/controlled statistical free-radical copolymerization. Prog. Polym. Sci., 2002, v. 27, pp. 1879-1924. DOI: 10.1016/S00796700(02)00023-0

2. Barouti G., Jaffredo C. G., Guillaume S. M. Advances in drug delivery systems based on synthetic poly(hydroxybutyrate) (co)polymers. Prog. Polym. Sci., 2017, v. 73, pp. 1-31. DOI: 10.1016/j.progpolymsci.2017.05.002

3. Kabanov A. V., Vinogradov S. V. Nanogels as pharmaceutical carriers: finite networks of infinite 
capabilities. Angew. Chem. Int. Ed., 2009, v. 48, pp. 5418-5429. DOI: 10.1002/anie.200900441

4. Oh J. K., Drumright R., Siegwart D., Matyjaszewski K. The development of microgels/nanogels for drug delivery applications. Prog. Polym. Sci., 2008, v. 33, pp. 448-477. DOI: 10.1016/j.progpolymsci.2008. 01.002

5. Kuznetsov V. A., Lavlinskaya M. S., Ostankova I. V. Synthesis of N-vinylformamide and 1-vinyl-(1methacryloyl)-3,5-dimethylpyrazole copolymers and their extraction ability in relation to histidine in watersalt media. Polym. Bull., 2018, v. 75, pp. 1237-1251. DOI: 10.1007/s00289-017-2091-2

6. Bhattacharya A., Misra B. Grafting: a versatile means to modify polymersTechniques, factors and applications. Prog. Polym. Sci., 2004, v. 29, pp. 767-814. DOI: 10.1016/j. progpolymsci.2004.05.002

7. Rasoulzadeh M., Namaz H. Carboxymethyl cellulose/graphene oxide bio-nanocomposite hydrogel beads as anticancer drug carrier agent. Carbohydr.
Polym., 2017,v. 168, pp. 320-326. DOI: 10.1016/j.carbpol.2017.03.014

8. Worzakowska M. Chemical modification of potato starch by graft copolymerization with citronellyl methacrylate. J. Polym. Environ., 2018, v. 26, pp. 16131624. DOI: $10.1007 / \mathrm{s} 10924-017-1062-\mathrm{x}$

9. Kuznetsov V.A., Kushchev P. O., Blagodatskikh I. V. Aqueous dispersions of cross-linked poly-N-vinylcaprolactam stabilized with hydrophobically modified polyacrylamide: synthesis, colloidal stability, and thermosensitive properties. Colloid. Polym. Sci., 2016, v. 294, pp. 889-899. DOI: 10.1007/s00396-016-3843-5

10. Genç F., Uzun C., Güven O. Quaternized poly(1vinylimidazole) hydrogel for anion adsorption. Polym. Bull., 2016, v. 73, pp. 179-190. DOI: 10.1007/s00289015-1479-0

11. Jakubiak-Marcinkowska A, Legan M, Jezierska J. Molecularly imprinted polymeric $\mathrm{Cu}(\mathrm{II})$ catalysts with modified active centres mimicking oxidation enzymes. J. Polym. Res., 2013, v. 20(12), pp. 317-328. DOI: $10.1007 / \mathrm{s} 10965-013-0317-\mathrm{z}$
Кузнецов Вячеслав Алексеевич - д. х. н., профессор, кафедра высокомолекулярных соединений и коллоидной химии, Воронежский государственный университет, Воронеж, Российская Федерация; e-mail: dr.v.kuznetsov@gmail. com. ORCID: 0000-0002-0072-2025.

Лавлинская Мария Сергеевна - к. х. н., М. н. с. базовой кафедры ЭФКО «Молекулярной биотехнологии», Воронежский государственный университет, Воронеж, Российская Федерация; e-mail: maria.lavlinskaya@gmail.com. ORCID: 0000-0001-9058-027X.

Сорокин Андрей Викторович - магистрант 2 года обучения, кафедра высокомолекулярных соединений и коллоидной химии, Воронежский государственный университет, Воронеж, Российская Федерация; ORCID: 0000-0001-5268-9557.
Kuznetsov Vyacheslav A. - Dr. Sci. (Chem.), Professor, Polymer Science and Colloid Chemistry Department, Voronezh State University, Voronezh, Russian Federation; e-mail: dr.v.kuznetsov@gmail. com. ORCID: 0000-0002-0072-2025.

Lavlinskaya Maria S. - Cand. Sci. (Chem.), Junior Researcher of Molecular Biotechnology, Voronezh State University, Voronezh, Russian Federation; e-mail: maria.lavlinskaya@gmail.com. ORCID: 0000-0001-9058-027X.

Sorokin Andrey $V_{.}-2^{\text {nd }}$ year education Master Student, Polymer Science and Colloid Chemistry Department, Voronezh State University, Voronezh, Russian Federation; ORCID: 0000-0001-52689557. 